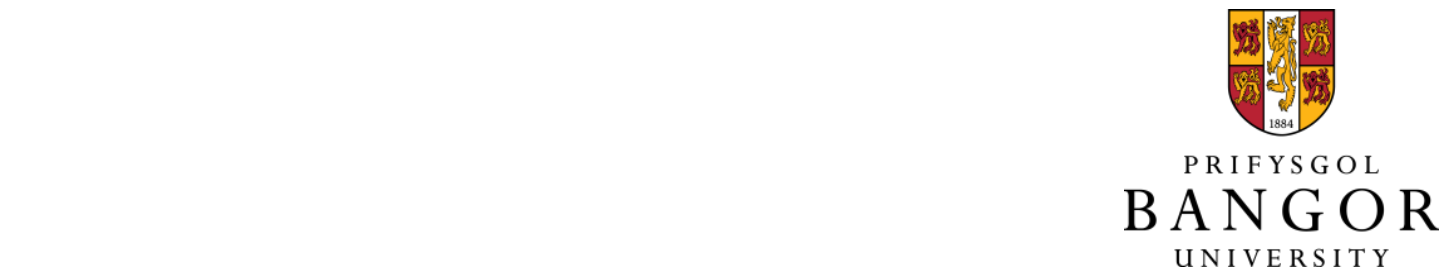

Going pro: Point of view cameras in adventure sports research

French, Graham

Journal of Outdoor and Environmental Education

Published: 01/04/2016

Peer reviewed version

Cyswllt i'r cyhoeddiad / Link to publication

Dyfyniad o'r fersiwn a gyhoeddwyd / Citation for published version (APA):

French, G. (2016). Going pro: Point of view cameras in adventure sports research. Journal of Outdoor and Environmental Education, 19(1), 2-9.

http://search.proquest.com/docview/1783062841 ?accountid=14874

Hawliau Cyffredinol / General rights

Copyright and moral rights for the publications made accessible in the public portal are retained by the authors and/or other copyright owners and it is a condition of accessing publications that users recognise and abide by the legal requirements associated with these rights.

- Users may download and print one copy of any publication from the public portal for the purpose of private study or research.

- You may not further distribute the material or use it for any profit-making activity or commercial gain

- You may freely distribute the URL identifying the publication in the public portal ?

Take down policy

If you believe that this document breaches copyright please contact us providing details, and we will remove access to the work immediately and investigate your claim. 
Going Pro

\section{Going pro: Point of view cameras in adventure sports research}

Graham French

School of Education

Bangor University

Normal Site

Holyhead Road

Bangor

LL57 2PZ

01248388598

g.k.french@bangor.ac.uk

Graham French is the director of postgraduate secondary education at the School of Education at Bangor University, Wales. He delivers modules in outdoor learning to trainee primary school teachers, and is course tutor to the secondary Outdoor Activities group. A qualified coach in several adventure sports including mountain biking and white-water paddling, his research interests include models of delivery of outdoor education, outdoor education curriculum design and developing outdoor learning resources for non-specialists. Away from academia, he is the adventure activities technical advisor for a national children's holiday charity, coach educator and trainer for the Mountain Bike Instructor's Award Scheme, and Canoe Wales.

\section{Abstract}

The role of the adventure sports coach was first identified by Collins and Collins (2012) who suggested that the sports coaching process is significantly different in an adventurous context. Whilst there is a growing body of literature surrounding coaching pedagogy (Hay, Dickens, Crudginton \& Engstrom, 2012), investigation of 
Going Pro

coaching pedagogy within adventure sports is less common. Video ethnography is a well-documented field, with a broad base in the literature across many fields of study, and as technology progresses, new applications of that technology become apparent and require investigation. This paper details the development of a new method of data capture for qualitative analysis in the field of adventure sports research/adventure sports coaching pedagogy, using point of view (POV) video cameras as the primary means of data capture. Ethical and philosophical concerns are considered with a brief evaluation of the technique and suggestions for future use and development.

\section{Introduction}

The role of the adventure sports coach has been documented by Collins and Collins (2012), and as my primary role at Bangor University is to train teachers and coaches of adventure sports, it was pertinent to research adventure sports coaching pedagogy. I recently initiated some research into models of provision of outdoor education in schools, and one of those models I considered was that of adventure sports in the physical education (PE) curriculum. If the adventure sports coaching process is significantly different from traditional sports coaching, then PE teachers will need to be educated in this specific area, as the transfer of coaching skills from traditional school sports cannot be readily relied upon. As Capel and Blair (2007) suggest, outdoor adventure is the area PE teachers feel least confident in delivering; 
Going Pro

therefore, it is relevant to investigate adventure sports coach pedagogy to better inform the training of PE teachers in this area.

As a coaching tool, use of video is well documented in both mainstream sport (Lyons, 1988) and adventure sports (Hoare, 2006). However, in these contexts the footage is used for analysis of performance of the individual/team, and to assist the coach in providing a detailed evaluation of performance and guidance towards improving that performance. Carson (2009) has written about the use of video to enhance the coaching process, using it as a review tool for the coach to look at their own coaching performance, but there appears to be a gap in the literature with regard to using video for qualitative investigation of coaching pedagogy, which itself is an emerging field with a burgeoning body of literature (Hay, Dickens, Crudginton, \& Engstrom, 2012).

The aim of this study was to implement and evaluate a new method of data capture whilst remaining aligned with methodological approaches previously demonstrated to be appropriate in this area. This is seen as a major challenge: to draw together strands from video anthropology, sport science, and outdoor education, to provide informative data on adventure sports coaching pedagogy. This paper's focus is on the new methods adopted to try to achieve this aim. The context for the research is summarised below, but the focus of the remainder of this article is the implementation and evaluation of the specific methods described.

\section{Context}


Going Pro

The adventure sports coaching process often uses a specific post-activity review session to embed learning (Taylor, 2006). It could be argued that this review process has been borrowed from adventure education where it is used to embed personal and social learning (Leberman \& Martin, 2004). However, there is a gap in the literature concerning the value of a specific, post-activity review session in an adventure sports coaching context, i.e. gaining technical skills in an adventure sport.

It was therefore considered worthwhile to examine the use of a specific review session in an adventure sports coaching context, and in designing the investigation the literature was thoroughly examined, looking for the background of this divergence from the use of reflection to embed affective learning. Throughout this process, I was also looking at the methodology and practical methods that had been used, to see how applicable they would be to the specific situation I had chosen to scrutinise - learning ice-climbing techniques. ${ }^{1}$ This process of searching for both theoretical justification and an appropriate methodology led me to adopt a new approach, and what followed was a journey into participant observation and video ethnography.

\section{Research design and methodology}

To understand the effect of a review session on learning ice-climbing techniques, it was appropriate to adopt a mixed-method design for complementary purposes (Greene, Caracelli, \& Graham, 1989), as this has previously been demonstrated as effective in evaluating aspects of adventure sports leadership (Bunyan \& Boniface, 
Going Pro

2000). I used a quantitative measure constructed from techniques described by Gresham and Parnell (2009), based on observation of participants' ice-climbing ability. This allowed differences in performance to be quantified to identify any significant differences in performance between the first and second days of the course. It offered a baseline from which to work for the qualitative data analysis. The qualitative method employed was a video-ethnography (Banks \& Morphy, 1997; Sparrman, 2005) participant observation approach (Spradley, 1980). This data allowed an in depth insight into the processes, producing the results seen in the quantitative data. Thus, the two methods complemented each other - one assessing whether there was change, and the other helping to identify some of the apparent causes of the change, or lack thereof. The qualitative data-generation technique is the focus of this article.

Data were collected via video and field notes on weekend residential visits to Rjukan, Norway, with beginners' ice-climbing courses (each lasting the two days of the weekend). Students were of mixed gender and in the age range 18-45. Data were collected by three coaches (including myself) who were actively involved in coaching the students as well as observing them for the purposes of this research. Students were observed on the first day to assess their abilities in three areas: ice-tool placement, i.e. how and where they placed their ice axes and crampons, movement on the ice, and belaying ability. At the end of the first day, a random subgroup (approximately half the group, between five and seven students) conducted a review 
Going Pro

using the " $3 \mathrm{i}$ " model (Hickman \& Palmer, 2012). This review model is based on asking three general questions of the participants (they may be contextualised as appropriate): "What?", “So what?", and "Now what?" (relating to information, inference and implication - the three " $\mathrm{i}$ "s). This model was selected as it considers description, theory and critical information in the three phases, and was designed to be used in limited time, under stressful conditions (such as those likely to be experienced), and in relation to expeditions and adventure sports. Students were then observed on the second day in exactly the same way, with data collected as before, creating pre- and post-treatment data sets for both groups.

The qualitative aspect of the data was analysed thematically using the NVivo software package, which allowed coding of video segments in addition to the coding of the field notes. Originally, one of the main reasons for using video had been to reduce the need to write field notes in sub-zero temperatures and strong winds (such as those often experienced whilst ice climbing) and following the idea that video recordings can form the main research data as opposed to merely complementing field notes (Banks \& Morphy, 1997).

The video data was also used for ensuring both intra-rater and inter-rater reliability (Armstrong, Gosing, Weinman, \& Marteau, 1997; Mays \& Pope, 1995). The intrarater reliability was conducted by re-watching all the video footage, not only as primary data, but also in light of the initial and subsequent coding analysis. The reviewing of original data in companion to previous interpretations/theming has 
Going Pro

been encouraged in outdoor adventure research by Rea (2008) as a technique to uncover that which may be missed on previous passes over the data. Inter-rater reliability (Armstrong et al., 1997) was sought by allowing a colleague to access the video data and conduct his own thematic analysis. He also made several passes over the data following the procedure used for intra-rater reliability. I then examined and re-analysed the combination of our thematic analyses in order to propose common and overarching themes.

\section{Going Pro: The focus}

The investigation focused on using video footage to investigate the value of a review/reflection session at the end of an activity session. It did not seek to use the video footage in or for that reflection process (the usefulness of which has been well documented by authors such as Lyons (1988) and Hoare (2006)). Thus, the procedures described here document the research process into a coaching method, not the actual coaching method in question.

In order to ensure generation of qualitative data was practical, yet unobtrusive, I opted to use a point of view (POV) video camera. A POV camera is a small video camera, typically not much bigger than a smartphone. It is usually worn on a helmet or chest harness, or may be attached to objects such as mountain bike handlebars. Popular models include the GoPro Hero series and the Contour Roam series, among many others. In practice, GoPro is becoming the genericised name for all POV cameras and there is a linguistic modification already occurring in the adventure 
Going Pro

sports sub-culture, in that GoPro is becoming "verbified"; that is, to gopro something is to perform or complete a task whilst being recorded with a POV camera. A POV is in effect a point and shoot video camera in that operation involves simply an off/on switch and the camera's electronics do the rest to optimise the image recorded. Most feature one-touch recording, and although some feature a built-in screen to see where the camera is aimed, this is uncommon as screens are a weak point in an otherwise tough casing. The problem of making sure the camera is actually pointing at what the user is seeing is countered in several ways. Firstly, the use of a wide angle, fisheye lens gives approximately 170 degrees of field of view. Although this distorts the perspective of that which appears at either side of the field of view, it does capture a wide area as long as the camera is pointed in the general direction of where the user is looking. Secondly, some models feature wireless connectivity to allow the camera to transmit its signal to a suitable app on a smartphone. Thus, a shot can be checked on the smartphone screen before filming commences. Some models also incorporate a laser pointing/positioning function, projecting a line or dot at the same point as the centre of the camera lens.

A POV camera can be less obtrusive than a handheld camera, partly as it is small and worn on the head/helmet, and partly as POV cameras are popular with, and therefore familiar to, adventure sports participants. They also have the advantage of being waterproof, resistant to low temperatures, and are easily portable. Most have a battery life of several hours' continual recording and can easily collect this amount 
Going Pro

of video footage on a high-density compact memory card. These characteristics make them ideal for filming where conventional cameras may be unsuitable, for instance if both hands are needed for a task, or in adverse conditions.

This unobtrusive approach to using video is important, as the process of being observed by a camera can alter behaviour (Cromdal, 2000; Foucault, 1991; Sparrman, 2005). Authentic participant observation as a complete participant (Spradley, 1980) is often difficult to achieve as it is obvious that the observer is making notes or taking footage; use of POV video better allows this complete participation which is important to further reduce the effect the camera has on the subject's behaviour (i.e., they become accustomed to being filmed, and behave more as they would without the camera).

\section{Ethical considerations}

Ethical clearance for this research was obtained through the standard university procedure (see acknowledgments), and students gave informed consent to participate. Specific mention was made of the sharing of video evidence for reliability procedures to be conducted after the residential courses had ended. Once data was collected, names were changed on the data capture instrument so that all future processing/analysis of the raw data remained confidential. Any mention of names was also "bleeped" out on the video footage for the same reason. 
Going Pro

Using video-ethnography as the main source of data generation (Banks \& Morphy, 1997) has some additional ethical considerations that would not arise through traditional participant observation. Pink (2001) comments that visual methods are rarely purely visual; they incorporate cultural expressions such as gestures, text, and the identities of participants. Thus, it is important to acknowledge that adventure sports have their own socially constructed behaviours, gestures, and language. It was to the advantage of this research that one of these cultural norms in the adventure sports sub-culture is the use of POV cameras to capture, re-live, and share experiences via video-sharing websites such as YouTube and Vimeo. However, it is important to consider reflexivity on the part of the researcher in using this approach (bearing in mind it is being used as a method of data capture, for inter- and intrarater reliability in interpretation).

First-person camera views have been linked to specifically identifying with that person's views and feelings generated by what they see (Mulvey, 1975/1992; Stacey, 1994). Reflexivity may be compromised unless the use of the POV camera is specifically used to capture information only from this perspective, i.e. first-person identification is intentional. This is particularly relevant to this research as the video footage was used for conducting inter-rater reliability with another, independent colleague viewing the video. The influence of social and cultural constructions of the meaning of vision (Mirzoeff, 1988; Mitchell, 2002) are important factors to be aware of to maintain criticality in data interpretation, and hence reflexivity, in relation to 
Going Pro

the epistemology as well as the personal. Sparrman (2005, p. 250) states, "the recorded material per se also becomes a social and cultural statement," which fits with the adoption of a social constructivist ontology (Burr, 2003; Gergen, 1999). This perspective is endorsed by Rea (2008) who suggests that education (and by inference, coaching) is a socially constructed entity. So it can be seen that an appropriate epistemology is endorsed from different corners: one of practical methodology and its characteristics, and one of theoretical foundation.

Sparrman's work, referenced above, was specifically looking at children and their responses to video-ethnography, so although using adults as subjects leads to less concerns with putting them on display (in video footage) it was still important to maintain anonymity through the process. It should be noted that the footage collected during this investigation was only used for analytical purposes and was not displayed publically. There potentially could have been issues of image quality (unlikely when using HD automatic video cameras) or scene structure, as the filming was not to be used for the production of an ethnographic documentary (Ruby, 1995). However, these potential flaws also allow a genuine look at the subjects and their actions/performance in relation to changing weather/light conditions, so in this sense they add to the authenticity of the data.

\section{The process: Goproing data}

In practice, actually using the POV camera to collect data was straightforward. It required some discipline on my part to make sure I observed the entire group in 
Going Pro

their first hour or so of climbing each day, but as the nature of the area was small and contained this was easily facilitated (for a detailed description see Haukåssveen \& Bordevik, 2005). A colleague was directing the course, with myself and another colleague acting as assistant coaches. As well as coaching the group in basic techniques, we were each collecting quantitative data via a categorised tick-sheet, with space for taking notes (to explain a tick if it may be unclear to another observer why this tick had been placed in a particular box). The main qualitative data was the video footage itself (as described by Banks \& Morphy, 1997) and this had a number of serendipitous consequences that can be directly attributed to using the POV method as opposed to a fixed tripod-based or handheld camera.

Use of a POV camera allowed complete participation in that I was able to fulfil my role as coach and researcher simultaneously and symbiotically. Whilst as a coach it can be difficult to circulate round a whole group as opposed to focusing on those students who need most help, (Timms, 2006) the knowledge that I needed to collect video footage of each participant acted as a motivator to circulate throughout the group, and observe and comment on each person individually. In return, the fact that I had a professional responsibility to coach and improve the performance of each student meant I was motivated to observe them for a period of time that would be sufficient for intervention; this also meant I captured video footage of that person for later analysis. 
Going Pro

The hands-free nature of POV recording meant that I could belay each student; this lends itself to detailed observation of that person. As a belayer, it is vitally important to maintain a close eye on your climber so you may take in or pay out the correct amount of rope to allow them to move freely, yet have the protection of the rope should they fall. This is also in the interest of your own personal safety; should there be too much slack rope between belayer and the climber and the climber falls, there will be a significant force on the belayer that may pull them off their feet or into the air as a counterbalance to their climber. Thus, complete participation (Spradley, 1980) can be seen to enhance the data-generation aspect of this research.

Video recording has the advantage that it captures a whole scene; details that may be missed by eye in the moment are noticed at a second or third pass over the footage (Sparrman, 2005). The 170-degree fisheye lens on the POV camera captured additional evidence to that which could have been recorded in field notes through direct observation. The nature of the climbing area was small and confined, so climbers were often climbing routes in close proximity to one another. Thus, although my attention could be entirely focused on one particular climber, it was possible to observe the action of a nearby climber on the second pass over the footage. This became evident and more useful as the data was analysed; it also became clear that although POV cameras are widely accepted in adventure sports, participants did behave slightly differently whilst being filmed, probably because 
Going Pro

they were aware of the research process, its focus, and methodology (having given informed consent to being part of the process).

This altered behaviour is in contrast to the idea expressed earlier that a POV camera would remove this effect. It demonstrates the power that being observed has on an individual (Foucault, 1991). In this context, the effect on the participants was far less than that documented by Sparrman (2005). However, this subtle change in behaviour was particularly evident when observing the skill of belaying (that is holding/controlling the rope attached to a climber). Belaying is a precise and complex combination of motor skills, requiring both a linear step-by-step process and an intuitive feeling for how much rope to take in, based on observation of the climber's position, perceived ability, body language, and fatigue levels. Good belaying requires a high degree of concentration, and the nature of climbing in a group in close confines means that there is inevitable social interaction between the belayers and non-climbers on the ground. Thus, when not under direct scrutiny it is easy for less experienced belayers to socialise whilst belaying and hence, concentrate less on their climber.

More experienced climbers were better able to converse and still maintain a high degree of concentration; the act of belaying well has become instinctive and they are more attuned to the feedback from the feeling in the rope, as well as observing their climber whilst talking. Less experienced climbers tended to concentrate more when they knew they were being directly observed. The second and third passes over the 
Going Pro

footage showed less concentration on the part of the belayer when they perceived they were not being filmed. This is in agreement with Foucault's (1991) findings that subjects will behave differently when they perceive they are being directly observed. Sparrman (2005) observed a variation on this with children, in that they sometimes acted specifically towards the camera, as well as differently, because they knew they were being filmed. Although the subjects in this research were adults, some of their behaviour can be compared to that of the children in Sparrman's work, as they were observed to be emboldened by the presence of the camera and sometimes spoke directly to the camera (removing in that instant the first person association noted by Stacey, 1994). This can be seen as a link to the cultural meaning of the video camera (Sparrman, 2005) and in this case, the more specific cultural meaning of a POV camera (in adventure sports).

\section{Limitations of use}

As already stated, there is an inherent association in a first-person approach with the feelings and position experienced by the videographer (Mulvey, 1975/1992) that is seen in the POV camera as the ultimate first-person video perspective. Therefore, observations are by their nature personal to the researcher with the camera. This has an advantage in that the data-generation process closely mimics that which would be followed by taking ethnographic field notes, and further supports Banks and Morphy's (1997) assertion that video footage can be the main data collected, not just a complement to written field notes. 
Going Pro

A more traditional approach to video ethnography, whereby a camera is installed on a tripod in an area and then left by the researchers to capture what it will (Eriksson, 2002; Tholander, 2002) was considered, but in this situation there are practical factors that make this approach inappropriate. Conditions in which a normal tripod/handheld camera may become inoperable are commonly encountered in adventure sports and in particular whilst ice climbing. There is also the issue of capturing a whole group's performance - it may be possible to rig a camera so that it covers one route, but the nature of climbing routes having subjective difficulty means that climbers will perform differently on one route to another, so to gauge overall performance and observe changes in this performance, there must be flexibility and scope to cover many routes so as to gain a true picture of the climber's ability. The practical difficulty in setting up a conventional tripod on soft powder snow (surrounding the icefalls) and maintaining its line of sight (as the snow shifts and moves/melts under the influence of sun and wind) also precluded this approach.

Another approach is to use a camera on a tripod but to move it at certain points during the data-generation process, as espoused by Sparrman and Eriksson (2005), cited in Sparrman (2005). In this instance, the issues of inoperability in extreme conditions are not addressed, but there is more scope for gaining a variety of data. The implication is that a researcher being present would allow for movement of the 
Going Pro

camera to attend to serendipitous occurrences, and the interaction of the subjects and the researcher (and the camera) would be freer (Cromdal, 2000; Sparrman, 2002).

The video footage collected by the POV camera had some peculiarities. These may not have been encountered if using either of the [alternative] methods mentioned above. It became apparent that the procedure for using POV video could also be modified to provide data in a form more suitable for qualitative analysis. A number of these alterations to experimental procedure are detailed below.

With a helmet-mounted camera there is good coverage of the range of view experienced by the researcher (i.e. the wearer of the helmet and hence, camera). However, when watching the footage it became apparent how often the wearer turns their head to look at someone speaking to them, or has a general look round at the group. This was perhaps exaggerated, as in this case the wearer was one of the coaches and had a primary responsibility for the safety of group members (participating in a potentially hazardous activity, ice climbing). In review, this can make the watcher experience symptoms not unlike motion sickness, as the visual horizon is changing constantly and quickly. Thus, a carefully edited form would be necessary to avoid this, but there are then questions of what to edit; the research starts to become an ethnographic documentary (Ruby, 1995) that has its own set of ethical considerations. Sparrman (2005) identifies one strength of video ethnography as its ability to observe all, and not have an editorial or aesthetic bias. To minimise this, the wearer needs to practice the use of a POV camera to produce a steady shot. 
Going Pro

This is hard to achieve unless there is some kind of instant, visual feedback, such as the smartphone apps associated with the higher-end models such as the Go Pro Hero 4.

Complete participation (Spradley, 1980) as a form of participant observation has its own set of considerations, and these are further highlighted by the use of POV video. As already stated, whilst participating as a coach and simultaneously conducting research there are advantages to both processes. However, it would be disingenuous not to consider the downsides to this specific instance of complete participation. Coaching as an activity is complex and includes components related to the coach's experience and training, as well as their motivation (Taylor, 2006). This presents a problem when the coach uses their experience and perhaps observations of red-flag activities or movements to identify common areas for improvement (as is often the case when coaching beginners in adventure sports (Timms, 2006)). This experience and diagnostic skill in coaching may not be apparent to the camera and thus, the amount of footage is less than ideal for the inter-reliability procedure to be carried out later. In this instance, a less experienced coach would be more advantageous to the researcher as they would need longer periods of observation to diagnose and coach skilful behaviour in the student. However, there is an inherent conflict here in the length of time the coach can observe for, and the benefit to the participant. A more experienced coach can identify and progress a student more quickly, so the student perceives they have progressed further and gained better 
Going Pro

value for money or value for time dependent on the context. In this instance, the advantages of POV video may be maintained by using an independent researcher who is actively part of the group but not engaged in the coaching process, that which Spradley (1980) details as the passive participant.

A practical compromise may be to use more than one camera - the rugged, tough construction of POV cameras lends itself to adventure sports research as an application, but it may be prudent to use several cameras to gain a broader and balanced view of the activity. This may involve a head- or body-mounted camera on an observer (not necessarily the coach) complemented by a camera on a tripod or other mounting (in practice, a spare POV camera was mounted in a snow bank using a mount meant for making the camera float in water to gain video footage of the group not connected with this research). This would bring the advantages of POV first-person perspective (and hence reflexivity), but also allow a complementary viewpoint on highly mobile or visually challenging footage.

\section{POV in adventure sports research: Concluding remarks}

Whilst the rise in popularity in adventure sports of the POV camera may seem like an ideal opportunity to take a different stance on ethnography and participant observation, it is still an emerging form of data capture. It should be subject to the same critical scrutiny as all video-based ethnography (Sparrman, 2005) as it is essentially a specialised offshoot of this area of research. It has great practical appeal to those working in extreme conditions, such as those often experienced by 
Going Pro

adventure sports researchers, but the practicalities need to be tempered with appropriate methodological and ethical considerations.

This paper has sought to outline one specific use of a POV camera as a primary data collection tool, and discussed some of the philosophical and ethical considerations associated with a practical method of this kind. However, it should be noted that this is within the context of adventure sports coaching research, which is itself an emergent field (Collins \& Collins, 2012), and so transferring the process and hence advantages to other traditional areas of research may be more challenging and require further investigation into the limitations of application.

4685 words

\section{Notes}

1. I had chosen to examine ice climbing, as during the winter season (January to March) I run several beginner ice-climbing courses as part of my work with trainee teachers, offering an appropriate-sized pool of subjects.

\section{Acknowledgements}

I would like to acknowledge the assistance of Tom Brodie and Damien Baxter of Fjellogpadleskole, Norway in collecting the data, and Ian Martin of St David's College, Llandudno in conducting the inter-rater reliability process. 
Going Pro

This research stemmed from a mini-project I completed as part of a module for an MA in Outdoor Education at the University of Wales, Trinity St David, Carmarthen, and as such, I would like to thank the module supervisor Dr Nalda Wainwright and course organiser Dr Andy Williams for their invaluable guidance during the research process.

\section{References}

Armstrong, D., Gosing, A., Weinman, J., \& Marteau, T. (1997). The place of interrater reliability in qualitative research: An empirical study. Sociology, 31(3), 597-607.

Banks, M., \& Morphy, H. (1997). Rethinking visual anthropology. New Haven CT/London, England: Yale University Press.

Bunyan, P. S., \& Boniface, M. R. (2000). Leader anxiety during an adventure education residential experience: An exploratory case study. Journal of Adventure Education and Outdoor Learning, 1, 37-44.

Burr, V. (2003). Social constructionism (2nd ed.). Hove, England: Routledge.

Capel, S., \& Blair, R. (2007). Making physical education relevant: Increasing the impact of initial teacher training. London Review of Education, 5(1), 15-34.

Carson, F. (2008). Utilizing video to facilitate reflective practice: Developing sports coaches. International Journal of Sports Science and Coaching, 3(3), 381-390. 
Going Pro

Collins, L., \& Collins, D. (2012). Conceptualizing the adventure-sports coach. Journal of Adventure Education and outdoor Learning, 12(1), 81-93.

Cromdal, J. (2000). Code-switching for all practical purposes: Bilingual organisation of children's play. Linköping Studies in Arts and Science, 233, Linköping, Sweden: Linköping University Press

Eriksson, K. (2002). Life and fiction: On intertextuality in pupils' booktalk. Linköping Studies in Arts and Science, 251. Linköping, Sweden: Linköping University Press.

Foucault, M. (1991). Discipline and punish: The birth of the prison. Harmondsworth, England: Penguin Books.

Gergen, K. J. (1999). An invitation to social constructionism. London, England: Sage.

Greene, J. C., Caricelli, V. J., \& Graham, W. F. (1989). Toward a conceptual framework for mixed-method evaluation designs. Educational Evaluation and Policy Analysis, 11(3), 255-274.

Gresham, N., \& Parnell, I. (2009). Winter climbing +. Sheffield, England: Rockfax Haukåssveen, J. \& Bordevik, T. A. (2005) Heavy water-Rjukan ice. Sheffield, England: Rock Fax

Hay, P., Dickens, S., Crudgington, B., \& Engstrom, C. (2012) Exploring the potential of assessment efficacy in sports coaching. International Journal of Sports Science and Coaching, 7(2), 187-198. 
Going Pro

Hickman, M. \& Palmer, C. (2012) The 3i model - a guide to critical reflective analysis in

Outdoor Education; information, inference and implication. Presentation at the British

Educational Research Association Annual Conference, London Institute of Education, 4th -6 th September

Hoare, L. (2006) Use of Video. In Ferrero, F. (Ed) British Canoe Union coaching handbook: A manual of coaching techniques, advice $\mathcal{E}$ guidelines for the canoe and kayak coach. Y Felinheli, Wales: Pesda Press

Leberman, S. \& Martin, P. (2004) Enhancing transfer of learning through post-course reflection Journal of Adventure Education E Outdoor Learning, 4(2), 173-184.

Lyons, K. (1988) Using video in sport Huddersfield, England: Springfield

Mirzoeff, N. (1998) The Visual Culture Reader London, England/New York, NY:

Routledge

Mitchell, W. J. T. (2002) Showing seeing: a critique of visual culture Journal of Visual culture, 1, 165-81.

Mulvey, L. (1975/1992) The Sexual Cinema: a screen reader in sexuality. London, England/New York, NY: Routledge

Pink, S. (2001) Doing visual ethnography: images, media and representation in research. London, England: Sage Publications 
Going Pro

Rea, T. (2008) Methodology in outdoor research: approaches from an alternative discourse Journal of Adventure Education \& Outdoor Learning, 8(1), 43-53.

Ruby, J. (1995) The moral burden of authorship in ethnographic film. Visual Anthropology Review, 11, 77-82.

Sparrman, A. (2002) Visuell kultur i barns vardagsliv _ bilder, medier och praktiker [Visual culture in the everyday life of children _/ pictures, media and practices]. Linköping studies in arts and science, 250. Linköping, Sweden: Linköping University Press

Sparrman, A. (2005) Video recording as interaction: participant observation of children's everyday life. Qualitative Research in Psychology, 2(3), 241-255.

Spradley, J. P. (1980) Participant Observation. London, England: Harcourt Brace Jovanovich College Publishers

Stacey, K. (1994) Star gazing: Hollywood cinema and female spectatorship. London, England/New York, NY: Routledge

Taylor, B. (2006) Coaching. In Ferrero, F. (Ed) British Canoe Union coaching handbook: A manual of coaching techniques, advice E guidelines for the canoe and kayak coach. Y Felinheli, Wales: Pesda Press 
Going Pro

Tholander, M. (2002) Doing morality in school: teasing gossip and subteaching as collaborative action. Linköping Studies in Arts and Science, 256. Linköping, Sweden: Linköping University Press.

Timms, B. (2006) Coaching Novices. In Ferrero, F. (Ed) British Canoe Union coaching handbook: A manual of coaching techniques, advice $\mathcal{E}$ guidelines for the canoe and kayak coach. Y Felinheli, Wales: Pesda Press 